\title{
Effect of Telenursing Intervention Program on Mothers' Knowledge about Postoperative Care for One Day Surgery Children
}

\author{
Hanem Abdullah Mohamed ${ }^{1}$, Naglaa Fathy Mahmoud ${ }^{2}$ \\ ${ }^{1}$ Lecturer of pediatric Nursing, Faculty of Nursing, Cairo University, Egypt \\ ${ }^{2}$ Assistant professor of pediatric Nursing, Faculty of Nursing ,Cairo University, Egypt
}

\begin{abstract}
Background: In this 21st century, the need for health services continues to experience rapid changes, telemarking is delivering nursing care and conducting nursing practice by using technology. The recovery after one day surgery is often troublesome for mothers often feel insecure regarding optimal post-operative care for their children after discharge from hospital. Aim: The present study aimed to evaluate the effect of telenursing program on mothers' knowledge about postoperative care for one day surgery children. A quasi-experimental research design (pretest/post-test design) was utilized in the present study. The study was conducted at three pediatric hospitals affiliated to Cairo University. Subjects and method: A purposive sample of 60 mothers and their children from the previously mentioned settings were included in the study and divided equally to study and control group. Tools of data collection included three tools: a structured interview questionnaire sheet to assess mothers and their children's personal characteristics; assessment sheet of mothers' knowledge about one day surgery postoperative care and follow up phone call record form. Results: The results of this study indicated highly statistically significant differences concerning mothers' knowledge preimplementation/post implementation of telenursing intervention program Conclusion: The study concluded that telenursing intervention program positively improved mother's knowledge in study group after implementation than before. Recommendation: Telenursing intervention program should be established to improve mothers' knowledge about post-operative care for one day surgery children.
\end{abstract}

Key words: children, telenursing, postoperative, mothers' knowledge, one day surgery 


\section{Introduction}

Pediatric day surgery has become increasingly prevalent in during recent years. Pediatric procedures eligible for day surgery have also been more frequently produced mainly because of the improvement in minimally-invasive surgical techniques, the development of new general anesthetic drugs and the wider use of regional anesthesia ${ }^{(1)}$. Nowadays, $60 \%$ to $80 \%$ of operations in a modern pediatric hospital are performed on a day surgery basis. The major advantages of this trend consist in the lessening of psychological stress for children and parents and the reduction in hospital costs, fewer staff required, and reduction frequency of nosocomial infections and length of surgical waiting lists ${ }^{(2)}$.

Some of the pediatric surgical nursing challenges are management of knowledge deficit in parents, monitoring of compliance to drug administration, reported that post-operative care including, pain relief, wound care and prevention of infection ${ }^{(3)}$. One day surgery for children requires good excellent nursing care that respond to the needs of children and parents. The most frequent complications include nausea and vomiting, sore throat, and discomfort at the surgical site, infection and bleeding ${ }^{(4)}$ as well as postoperative airway clearance and a rapid return to normal fluid and food intake ${ }^{(5,3,6)}$. Australian Confederation of Pediatric and Child Health Nurses (2016) $)^{(7)}$ emphasized that nurses play an important role in supporting parents to care for their children, by facilitating parents' knowledge and skills development through parent education. Parents should receive clear instructions on follow-up and written information on arrangements to deal with any postoperative emergency. Discharge from day surgery is now a common occurrence but requires experience and an understanding of the criteria for each intervention. Discharge planning must embrace needs of the individual child and their family. In order to develop and maintain a high-quality service, discharge planning in day surgery should begin before the child is admitted to the unit ${ }^{(2,8,9)}$. Technology development can change nursing practice. It can help nurses deliver nursing care for patients, families, and communities. Telenursing (TN) can be an alternative strategy in providing nursing care rather than face to face method. Telenursing is delivering nursing care and conducting nursing practice by using technology. There was some evidence related to application of telenursing in nursing practice and reported that it could 
be used for consultation, education, monitoring, and the evaluation of health care outcomes $^{(10,5)}$.

According to the Pan American Health Organization (PAHO) (2019) (11), telehealth entails the delivery of health services using information and communication technologies (ICT), where distance is a limitation for health services. In developing countries, telehealth is important for improving health systems, since it enhances the supply of services, streamlines diagnoses and treatment, overcomes geographical distances, improves quality, and contributes to professional training ${ }^{(12)}$.

The use of the mobile phone via text messaging is effective in enhancing the knowledge and the adherence of patients on an appropriate program toward health promotion and prevention of complications. The telenursing process and scope of practice are the same as in the traditional way whenever a large physical distance exists between the patient and the nurse. This new field of nurses' activities has expanded in many countries ${ }^{(13)}$.The innovation of telenursing technologies is diverse, such as mobile phones, smart phones, computers, Internet, videoconference, and telemonitoring equipment ${ }^{(14,15)}$.
Kim and $\mathrm{Yu}^{(5)}$ studied the effects of a Post Discharge Management Program (PDMP) using Mobile Instant Messenger (MIM) on parents' knowledge and state anxiety about postoperative care, and their children's compliance with care instructions after discharge, frequency of bleeding, and pain intensity. They illustrated that parents in the experimental group reported a significantly higher knowledge about post discharge management and lower state anxiety than the control group. Children in the experimental group showed a significantly greater improvement in compliance with the care instructions at home than the control group. However, bleeding frequency and pain intensity were not significantly lower in the experimental group than that in the control group.

Telenursing offers an access to care and the ability to export nursing care using technology. It is a powerful tool for overall improvement in healthcare. Several measures should be taken for telenursing implementation into practice for all nurses. Telenursing may support general nursing, which is facing a shortage of nurses nowadays, and the demand for telenurses is worldwide. To meet the patients' needs and with the current nursing shortage, many homecare agencies have to look at innovative ways to care for the increasing 
numbers of patients ${ }^{(16)}$. Zhang, Yuxia $(2020)^{(17)}$ reported that telenursing may be the best solution in the COVID-19 situation. Nurses have limited access to meeting children and their families face-toface. However, regarding It is noteworthy that technology is only a medium to deliver high-quality nursing care in the COVID-19 situation. The key of telenursing practice is Communication. Therefore, therapeutic relation between nurses-families and children is essential.

\section{Significance of the study}

The researches using telenursing in pediatric nursing care is very scanty in Egypt; however in as study by Abusaad and Sarhan (2016) ${ }^{(18)}$ to examine the effect of telenursing on depression and fatigue level in b-thalassemia major children. They recommended applying telenursing intervention to facilitate contact of pediatric patients with their physicians and nurses whenever they need. Anyhow, there is a need to shed the light on the use of telenursing as a tool of delivering nursing teaching to the parents who care for their discharged children after one day surgery to overcome the far distance of the children residence from hospital as well as to reduce the need of children to come to hospital during COVID-19 pandemic.

The researchers observed that in the selected setting of the study the routine procedures for the children undergoing one day surgery is to attend the surgical outpatient clinic for diagnosis, where the doctor give them a list of needed laboratory investigation and the nurse take the parent contact number. Then the secretary of the surgical unit call the parents one week before the operation day to inform them to carry out the laboratory investigation in any laboratory near to their home and to come in the morning of the day of the surgery with the child fasting at least 8 hours. After the operation is done the child is admitted to the recovery unit and when fully recovered (in few hours) the doctor give parents the medication sheet with few instruction related to time of feeding as well as the date of follow up in the surgical outpatient clinic one week after the operation. The parents are totally left alone to face the needs of their children post-operative care. Thus, the aim of the present study is to evaluate the effect of telenursing program on mothers' knowledge about postoperative care for children with one day surgery.

\section{Subjects and Method}

Operational definition: Mothers' knowledge about post- operative care for the present study is the mothers' knowledge about care of: child position after operation, nutrition, vomiting, bleeding, mobilization and activity, fever, 
air way and cough, pain, medication administration, intra-abdominal pressure, wound, urination, prevention of infection, and follow up.

\section{Aim of the study}

The aim of the present study is to evaluate the effect of telenursing program on mothers' knowledge about postoperative care for one day surgery children.

\section{Research hypotheses}

1- Mothers who will receive telenursing program are expected to be higher total knowledge score in posttest and follow up test than those mothers in control group.

2- Children of mothers who will receive telenursing intervention program will show fewer postoperative complins /complications than those children who their mothers did not receive the program.

\section{Research design}

A quasi experimental design is like a true experiment, a quasi-experimental design aims to establish a cause-andeffectrelationbetween an independent and dependent variable. However, unlike a true experiment, a quasi-experiment does not rely on random assignment. Instead, subjects are assigned to groups based on non-random criteria. Quasi-experimental design is a useful tool in situations where true experiments cannot be used for ethical or practical reasons. Quasi-experimental designs that use a control group are used when intervention $\mathrm{X}$ is implemented for one group and compared to a second group. The use of a comparison group helps prevent certain threats to validity including the ability to statistically adjust for confounding variables ${ }^{(19)}$.

\section{Setting}

The proposed study was conducted at three settings:

1- Surgical out-patient clinic at Cairo University Specialized Pediatric Hospital (CUSPH).

2- One day surgery unit $2^{\text {nd }}$ floor at Cairo University Specialized Pediatric Hospital (CUSPH) AlMonirah Hospital. It includes one operating room, waiting room for parents during surgery, and recovery room. Operations done per day ranges from 5-to 10 cases.

3- Follow up surgical clinic at Center for Social and Preventive Medicine (CSPM) Affiliated to Cairo University.

\section{Sample}

A purposive sample of 60 mothers and their children undergoing one day surgery were included in the study according to the inclusion criteria: Mother (any age, read and write, have a smart phone with internet access and what's app. Child of 
any age and diagnosis that its treatment a one day surgery.

The only exclusion criteria of the child have any chronic condition or disability

The first 30 mothers and their children were considered as the control group (received hospital routine care), while the second 30 mothers and their children were considered as the group (who received the telenursing intervention program).

The sample size calculation is based on type 1error 0.05 and power of test $95 \%{ }^{(20)}$.

\section{Tools of Data Collection}

Three tools used to collect data were developed by the researchers in Arabic language after reviewing the related literature:

\section{(Tool I): A Structured Interview}

Questionnaire: This tool is composed of the following parts:

Part I a- Mothers' characteristics as age, residence, level of education, marital status, heath status, and number of children,

b- Children characteristics as age, sex. (8 questions)

Part II -Medical history of the child which included: diagnosis, previous hospital admissions, and reasons of previous child hospital admission. (3 questions)

(Tool II): Mothers' Knowledge about One day Surgery Postoperative Care: It was developed to assess mothers' knowledge about postoperative; it included 45 questions as divided as follow: sleeping position after operation (1 question), child nutrition (3 questions), care of vomiting child (4 questions), activity (3 questions), care of feverish child (8 questions), care of air way and cough (4 questions), care of pain (4 questions), medication administration (1 question), prevention of increased intra-abdominal pressure (3 questions), wound care (5 questions), urinary system care (3 questions), infection prevention (4 questions), and follow up (2 questions).

\section{Mother Knowledge about Post- Operative Care Questionnaire:}

The questionnaire included 45 questions with multiple choices (wrong and correct choices) total correct choices were 118 . Each selected correct choice was scored as (1) point and incorrect as (0) point. The total points (118) were divided into 3 categories: 1) unsatisfactory level of knowledge is below (60\%) (0 to less than 70 points), 2) satisfactory level of knowledge from $60 \%$ to less than $(75 \%)$ (70 to less than 88 points), and 3) good level of knowledge from (74-100\%) (88118 points).

The knowledge data collection sheet covered main 13 topics of post-operative care namely: sleeping position after 
operation, nutrition, care of vomiting child, activity, care of feverish child, care of air way and cough, care of pain, medication administration, prevention of intra-abdominal pressure, wound care, urinary system care, infection prevention, and follow up.

(Tool III) Follow up phone call record

form: used to record on it each phone call date, time, duration, complication/concern discussed and instruction given to the mother. In the form also the researcher documented the follow up of the previously discussed concerns or problems and the progress of it with the mother.

\section{Intervention program}

Telenursing program was developed by the researchers after reviewing the literature and related researches. The program was prepared in the form of Arabic booklet about post-operative care for one day surgery children.

\section{Booklet content:}

Introduction about one day surgery, postoperative care of child after one day surgery regarding the following: child's position, nutrition, vomiting, child's movement, fever, breathing and cough care, post-operative pain, medication administration, increased intra-abdominal pressure, wound care, urine output, infection prevention, danger signs of infection after the operation and follow-up.

\section{Content validity}

Content validity was done to identify the degree to which the tools measure what was supposed to be measured .The tools were examined by a panel of five experts in the field of pediatric surgery and pediatric nursing. $98 \%$ of the experts agreed on the tool content and only minor corrections were done to the Arabic language of the tools to make it easily understood to mothers.

Mothers' Knowledge about One day Surgery Postoperative Care reliability:

Internal consistency was measured to identify the extent to which the items of the tool measure the same concept and the extent to which the items are correlated with each other .Internal consistency reliability was estimated by Cronbach's Alpha that was 0.90 .

\section{Ethical consideration}

An ethical approval was obtained from the research ethical committee in the Faculty of Nursing, Cairo University with approval reference number (2021-18). A written informed consent was obtained from mothers (in both control and intervention groups) after complete description of the purpose and nature of the study to obtain their acceptance as well as to gain their cooperation. They were informed about their voluntary participation and their right to withdrawal from the study at any time. 
Moreover, mothers were assured that all gathered information was kept confidential and used only for the purpose of the study.

\section{Procedure}

An official permission was secured from the directors of Cairo University Specialized Pediatric University Hospital as well as the head of day surgery unit and head of out-patient and The Director of Center for Social and Preventive Medicine (CSPM) Affiliated to Cairo University where the surgical follow up clinic is located. Researchers met the mothers in both groups in setting (1): the surgical outpatient clinic at Cairo University Specialized Pediatric Hospital (CUSPH) where they come for diagnosis. After simple clear explanation of study and its aim to the mothers who match the inclusion criteria, an informed consent was secured.

\section{A-For the control group (who receives}

\section{the hospital routine care):}

1- The researchers filled tool (I) Structured Interview Questionnaire, and Tool (II) Sheet of Mothers' Knowledge about One day Surgery Postoperative Care (pretest).

2- In the follow up surgical clinic at Center for Social and Preventive Medicine (CSPM). Researchers met the control group mothers and filled up tool (II) Sheet of Mothers'
Knowledge about One day Surgery Postoperative Care (posttest). The researchers recorded using Tool (III) the follow up sheet the presence of any complication or unresolved complaints after surgery.

3- After one month of operation researchers called mothers to fill tool (II) Sheet of Mothers' Knowledge about One day Surgery Postoperative Care (follow up test). Each phone call took 20-30 minutes

\section{For the study group:}

\section{Assessment phase:}

The researchers filled tool (I) Structured Interview Questionnaire, and Tool (II) Assessment Sheet of Mothers' Knowledge about One day Surgery Postoperative Care. Scores of tool (II) will be considered the pre-test for mothers' knowledge for intervention group. Directly after that, the researchers distributed the program booklet to the mothers; which was developed by the researchers in Arabic language. The researchers collected from the mothers their phone numbers and explained to them that the program booklet will be sent to them thorough What's App. The researchers asked the mothers to read the booklet then the sessions were arranged as per mothers' available time. 


\section{Intervention phase:}

The researchers made the first phone call for the mothers after two days of the meeting them in the surgical out-patient clinic, then sessions was arranged as per mothers' available time. The program was given in three sessions each session was on each other day and took 45 minutes long as follow:

Session one: included introduction about one day surgery, child sleeping position postoperatively, postoperative nutrition, car of child with vomiting, child mobilization and activities, and care of fever.

Session two: included air way maintenance and care of cough, pain, medication giving, intra-abdominal pressure, and wound care.

Session three: included urine output, infection control, signs of infection, follow up, and conclusion.

After finishing the sessions, the researchers remained available on phone as per mothers' need to explain any unclear content of the program.

On the operation day the researchers met the mother and children in setting (2) One day surgery unit $2^{\text {nd }}$ floor at Cairo University Specialized Pediatric Hospital (CUSPH) Al-Monirah Hospital. The researchers clarified to mothers any needed points regarding the postoperative care for their children. After surgery the researchers told mothers to call in case their children have any complaints and they need help in care provision to their children.

All phone calls were recorded using Tool (III) phone call record form in terms of date of phone call, duration, concern discussed and management given and follow up of child complaints/complications been discussed. There was an assigned pediatric surgeon from the surgical unit with whom the researchers could communicate regarding child complains.

\section{Evaluation phase 1 (post-test):}

After one week of the surgery the researchers met the mothers in setting (3); Follow up surgical clinic at Center for Social and Preventive Medicine (CSPM).The researchers filled tool (II) Sheet of Mothers' Knowledge about One day Surgery Postoperative Care as a posttest to evaluate the effect of the program on mother's knowledge about postoperative care for one day surgery children. The researchers reviewed the patient follow up sheet to document the presence of any post-operative complaints/complications occurred to the child. 


\section{Evaluation phase 2 (follow-up):}

One month after surgery the researchers called the mothers to fill over the phone tool (II) Sheet of Mothers' Knowledge about One day Surgery Postoperative Care as a follow up to evaluate the effect of the program on mother's knowledge about postoperative care for one day surgery children. Each call for mothers took about 20-30 minutes to fill the tool.

\section{Statistical analysis}

The collected data was tabulate and summarized using statistical package for social studies, version 21. Data was computerize and analyzed using appropriate descriptive and inferential statistical tests. Quantitative data was express as frequency and percentage. A comparison between qualitative variables was carried out by using parametric $\chi^{2}$ test., and comparison between quantitative variables was done by using parametric $t$. test and f. test. Correlation among variables was done using Pearson correlation coefficient. Statistical significance was considered at $\mathrm{P}$ value less than 0.05 .

\section{Results}

Table (1) showed that the mean age of the mothers in study and control group was $(24.73 \pm 23.108$ and $21.82 \pm 25.31)$ while the mean age of their children was $(2.74 \pm 1.91$ and 1.98 \pm 2.41 ) respectively. Concerning education of the mothers in study and control group; $53.3 \%$ and $70 \%$ had high school education in both groups sequentially. Urban residence was the place of $70 \%$ and $56.7 \%$ of study and control group. It was clear that majority of the both samples were married (96. 7\% and $90 \%$ ) in study and control group respectively. Regarding number of children half of study group mothers had three or more children while $56.7 \%$ of control group had two children. Male gender was dominant in children of study and control group with a corresponding percentage of (80\% and 63.3\%) sequentially. All Chisquare values were at non-significant $P$. value which reflect the homogeneity of study and control group.

Table (2) illustrated a homogeneity between study group and control group regarding medical history and current health status of mothers variables with chi square test at P. levels higher than 0.05.; except for diagnosis and causes of previous hospitalization $(\mathrm{p} .=0.037$ and 0.038 respectively). The same table showed that $(63.3 \%$ and $66.7 \%)$ of children in both study and control group had experience of hospitalization; while the causes of previous hospitalization was due to bronchial asthma in $(47.4 \%)$ children in study group it was due to prematurity in $(60 \%)$ of control group children. 
Approximately two thirds of children diagnosis in study group (63.3\%) was inguinal hernia while in the control group (43.4\% and $33.3 \%$ ) were with hypospadias and umbilical hernia respectively. However the majority of mothers in both groups (90\% and 93.3\%) had no disease.

Table (3) reflected that score of mothers' knowledge in the study group about each area of post-operative care were unsatisfactory with percentage ranged between $(86.7 \%$ and $100 \%)$ in pre study group. While mothers knowledge were satisfactory with a percentage ranged between $(93.3 \%-100 \%)$ in post study and (40\%-100) in the follow up. However, scores of mothers' knowledge in the control group about each area of postoperative care were unsatisfactory with percentage ranged between $(86.3 \%-100 \%$, 80\%- $96.7 \%$ and $90 \%-100 \%)$ pre, post and follow up respectively.

Table (4) displayed that all mothers in study group pre the program had unsatisfactory knowledge level while post the program $(80 \%)$ of the mothers in study group had satisfactory knowledge level in the follow up $(66.7 \%)$ of them had satisfactory knowledge score. The same table revealed that the total mean score of knowledge about post-operative care among mothers in the study group before the program was $(28.53 \pm 11.01)$ while after the program and in the follow up had increased to $(93.20 \pm 17.92$ and $73.03 \pm 9.59)$ sequentially. However, all mothers in control group had unsatisfactory knowledge level in the pretest while the percentage lowered to $(97.7 \%$ and $93.3 \%)$ in follow up and posttest sequentially. While the total mean score of knowledge about post-operative care among mothers in the control group was $(28.53 \pm 11.01$, $31.003 \pm 3.62$ and $30.03 \pm 1.59)$ in pre, post and follow up successfully.

Table (5) revealed that there were positive highly statistical significant differences between the total mean scores of mothers' knowledge post and following the program of control and study groups with $(\mathrm{P} .=$ 0.000). While there was no statistical significant difference between the control and study group pretest total mean scores (t. = 1.370 and P. = 0.176). Meanwhile; there were positive highly statistical significant differences between pre, post and follow up of study group mothers' total mean scores of knowledge about postoperative care with $(P .=0.000)$.

Table (6) displayed that the study group mothers' scores in each area of the postoperative care: pre, post and follow up the program. It is very clear that the post scores of knowledge in each area of the thirteen areas had improved from pre scores except for medication 
administration which did not. This Change is clearly reflected by $f$. test that is $P$. value that of highly significant difference $(\mathrm{P} . \leq$ 0.004 and 0.000).

Table (7) clarified the presence of highly statistical difference between posttest level of knowledge about post-operative care in all the (13) area of care between control and study groups with $\mathrm{p}$. value varied between $(\leq 0.006$ and $\leq 0.000)$.

Table (8) highlighted the presence of highly statistical difference between follow up level of knowledge about post-operative care in all the (13) area of care between control and study groups with p. value varied between $(\leq 0.002$ and $\leq 0.000)$.

Table (9) clarified that the most frequent complain of children in control group were fever, bleeding, and vomiting (43.3\%, $26.6 \%$, and $23.3 \%$ sequentially) while in study group it was respiratory problems and pain (26.6\% and 23.3 respectively). Regarding complications (10\% \& 6.7\%) in control group children had abscess formation and urinary catheter removal respectively while the study group showed no complications. All children in the study group was managed by the researchers and the surgeon on phone while all the control group children presented to the surgical follow up clinic with the complaints.
Table (10) projected that total phone calls for mothers in the study group was (98) call. The minimum call phone duration was two minutes and the maximum was 20 minutes with a mean duration of $6.7755 \pm$ 4.33288 minutes.

Table (11) showed highly significance positive correlation between mother pre and post intervention knowledge scores; mothers' post and follow up knowledge scores (r. 0.430, 0.484, and 0.483) with p. value at $(\leq 0.01)$. The same table demonstrated a strong statistical negative correlation between mother age and follow up knowledge scores (r. - 0.459 and $\mathrm{P} \leq$ 0.01). However, the rest of child and mother socio-demographic variables had no significant relation to the knowledge test in both groups. 
Table (1): Socio-Demographic Data of Children and Their Mothers For Study and Control Group.

\begin{tabular}{|c|c|c|c|c|c|c|c|}
\hline \multirow{2}{*}{\multicolumn{2}{|c|}{ Item }} & \multicolumn{2}{|c|}{$\begin{array}{l}\text { Study Group } \\
\quad(\mathbf{N}=30)\end{array}$} & \multicolumn{2}{|c|}{$\begin{array}{l}\text { Control } \\
\text { Group } \\
(\mathrm{N}=\mathbf{3 0})\end{array}$} & \multirow[t]{2}{*}{$\begin{array}{c}\text { Chi square } \\
\text { test }\end{array}$} & \multirow[t]{2}{*}{$\begin{array}{c}P . \\
\text { value }\end{array}$} \\
\hline & & No & $\%$ & No & $\%$ & & \\
\hline \multicolumn{7}{|c|}{-Mother age (years): } & \multirow{5}{*}{0.834} \\
\hline- & $20->30$ & 17 & 56.7 & 16 & 53.3 & \multirow{4}{*}{0.364} & \\
\hline- & $30>40$ & 12 & 40 & 12 & 40 & & \\
\hline & $<40$ & 1 & 3.3 & 2 & 6.7 & & \\
\hline -Mea & \pm S.D. & \multicolumn{2}{|c|}{$24.73 \pm 23.108$} & \multicolumn{2}{|c|}{$21.82 \pm 25.31$} & & \\
\hline \multicolumn{2}{|c|}{-Mother education: } & & & & & \multirow{5}{*}{6.356} & \multirow{5}{*}{0.273} \\
\hline & Primary education & 4 & 13.3 & 1 & 3.3 & & \\
\hline & Prep-education & 4 & 13.3 & 5 & 16.7 & & \\
\hline & High school education & 16 & 53.3 & 21 & 70 & & \\
\hline- & University education & 6 & 20.1 & 3 & 10 & & \\
\hline \multicolumn{2}{|c|}{-Place of residence: } & & & & & \multirow{3}{*}{0.284} & \multirow{3}{*}{0.211} \\
\hline & Urban & 21 & 70 & 17 & 56.7 & & \\
\hline- & Rural & 9 & 30 & 13 & 43.3 & & \\
\hline \multicolumn{2}{|c|}{-Social status: } & & & & & \multirow{3}{*}{1.405} & \multirow{3}{*}{0.495} \\
\hline- & Married & 29 & 96.7 & 27 & 90 & & \\
\hline- & Divorced & 1 & 3.3 & 3 & 10 & & \\
\hline \multicolumn{2}{|c|}{-Number of children: } & & & & & \multirow{4}{*}{8.462} & \multirow{4}{*}{0.037} \\
\hline & One & 3 & 10 & 7 & 23.3 & & \\
\hline- & Two & 12 & 40 & 17 & 56.7 & & \\
\hline- & Three or more & 15 & 50 & 6 & 20 & & \\
\hline \multicolumn{2}{|c|}{-Child sex: } & & & & & \multirow{3}{*}{2.052} & \multirow{3}{*}{0.152} \\
\hline- & Male & 24 & 80 & 19 & 63.3 & & \\
\hline- & Female & 6 & 20 & 11 & 36.7 & & \\
\hline \multicolumn{2}{|c|}{-Child age in years: } & & & & & \multirow{5}{*}{2.24} & \multirow{5}{*}{0.299} \\
\hline- & $<1$ & 13 & 43.3 & 18 & 60 & & \\
\hline- & $1<5$ & 14 & 46.7 & 10 & 33.3 & & \\
\hline- & $>5$ & 3 & 10 & 2 & 6.7 & & \\
\hline -Mea & +S. D. & \multicolumn{2}{|c|}{$2.74 \pm 1.91$} & \multicolumn{2}{|c|}{$1.98 \pm 2.41$} & & \\
\hline
\end{tabular}

${ }^{*} \mathbf{P} \leq \mathbf{0 . 0 5}$ 
Table (2): Medical History and Current Health Status of Children and their Mothers For Study and Control Group.

\begin{tabular}{|c|c|c|c|c|c|c|}
\hline \multirow[t]{2}{*}{ Item } & \multicolumn{2}{|c|}{$\begin{array}{l}\text { Study Group } \\
\quad(n=30)\end{array}$} & \multicolumn{2}{|c|}{$\begin{array}{c}\text { Control } \\
\text { Group }(n=30)\end{array}$} & \multirow[t]{2}{*}{$\begin{array}{c}\text { Chi- } \\
\text { Square }\end{array}$} & \multirow[t]{2}{*}{$\begin{array}{c}\text { P. } \\
\text { Value }\end{array}$} \\
\hline & No & $\%$ & No & $\%$ & & \\
\hline $\begin{array}{l}\text {-Previous hospitalization of } \\
\text { Child: } \\
\begin{array}{ll}- & \text { Yes } \\
- & \text { No }\end{array}\end{array}$ & $\begin{array}{l}19 \\
11\end{array}$ & $\begin{array}{l}63.3 \\
36.7\end{array}$ & $\begin{array}{l}20 \\
10\end{array}$ & $\begin{array}{l}66.7 \\
33.3\end{array}$ & 0.73 & 0.787 \\
\hline $\begin{array}{l}\text { - Causes of child previous } \\
\text { hospitalization: } \\
\text { - } \quad \text { Bronchial asthma } \\
\text { - } \quad \text { Prematurity } \\
\text { - } \quad \text { Abdominal complains }\end{array}$ & $\begin{array}{c}9 \\
5 \\
5 \\
(n=19)\end{array}$ & $\begin{array}{l}47.4 \\
26.3 \\
26.3\end{array}$ & $\begin{array}{c}8 \\
12 \\
00 \\
(\mathrm{n}=20)\end{array}$ & $\begin{array}{l}40 \\
60\end{array}$ & 4.356 & 0.037 \\
\hline $\begin{aligned} & \text {-Child current diagnosis: } \\
& \text { - } \text { Inguinal hernia } \\
&- \text { Umbilical Hernia } \\
&- \text { Double inguinal hernia } \\
&- \text { Hypospadias }\end{aligned}$ & $\begin{array}{l}19 \\
1 \\
5 \\
5\end{array}$ & $\begin{array}{c}63.3 \\
3.3 \\
16.7 \\
16.7\end{array}$ & $\begin{array}{c}7 \\
10 \\
00 \\
13\end{array}$ & $\begin{array}{c}23.3 \\
33.3 \\
00 \\
43.4\end{array}$ & 14.204 & 0.038 \\
\hline $\begin{array}{c}\text {-Mother medical status: } \\
-\quad \text { No disease } \\
-\quad \text { Had disease }\end{array}$ & $\begin{array}{c}27 \\
3\end{array}$ & $\begin{array}{l}90 \\
10\end{array}$ & $\begin{array}{c}28 \\
2\end{array}$ & $\begin{array}{c}93.3 \\
6.7\end{array}$ & 0.218 & 0.640 \\
\hline
\end{tabular}

$* \mathbf{P} \leq \mathbf{0 . 0 5}$ 
Table (3): Knowledge Level of Mothers about Post-Operative Care in the Study and Control Groups in Percentage Distribution.

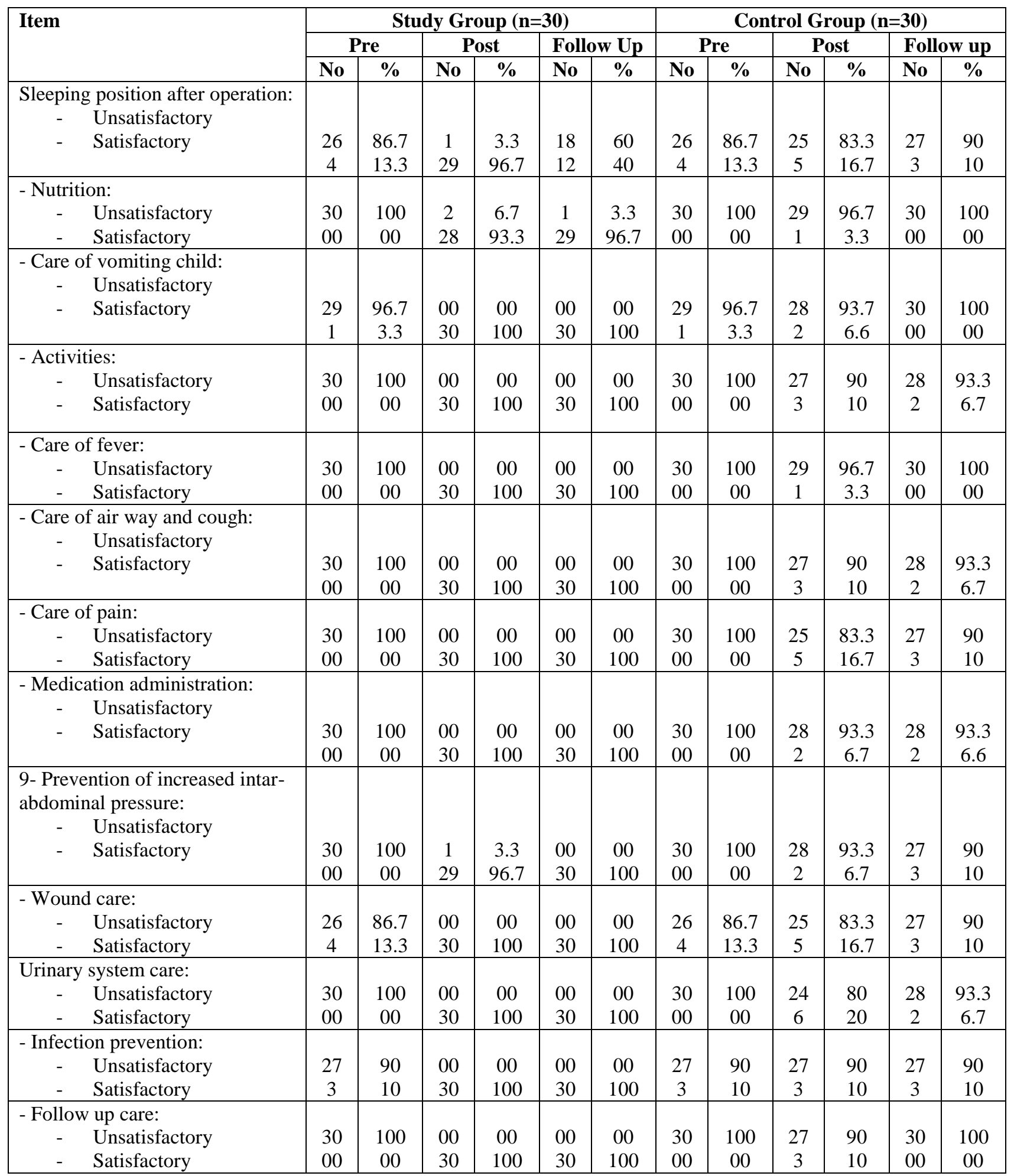


Table (4): Level and Total Mean Scores of Knowledge about Post-Operative Care Pre, Post and Follow up of Study and Control Groups.

\begin{tabular}{|c|c|c|c|c|c|c|c|c|c|c|c|c|}
\hline \multirow{3}{*}{$\begin{array}{l}\text { Item } \\
\text { Level: }\end{array}$} & \multicolumn{6}{|c|}{ Study Group $(\mathrm{n}=30)$} & \multicolumn{6}{|c|}{ Control Group $(\mathrm{n}=30)$} \\
\hline & \multicolumn{2}{|c|}{ Pre } & \multicolumn{2}{|c|}{ Post } & \multicolumn{2}{|c|}{ Follow up } & \multicolumn{2}{|c|}{ Pre } & \multicolumn{2}{|c|}{ Post } & \multicolumn{2}{|c|}{ Follow up } \\
\hline & No & $\%$ & No & $\%$ & No & $\%$ & No & $\%$ & No & $\%$ & No & $\%$ \\
\hline Unsatisfactory & 30 & 100 & 6 & 20 & 10 & 33.3 & 30 & 100 & 28 & 93.3 & 29 & 96.7 \\
\hline Satisfactory & 00 & 00 & 24 & 80 & 20 & 66.7 & 00 & 00 & 2 & 6.7 & 1 & 3.3 \\
\hline Mean \& S. D. & \multicolumn{2}{|c|}{$28.53 \pm 11.1$} & \multicolumn{2}{|c|}{$93.20 \pm 17.9$} & \multicolumn{2}{|c|}{$73.03 \pm 9.5$} & \multicolumn{2}{|c|}{$28.53 \pm 11.0$} & \multicolumn{2}{|c|}{$31.003 \pm 3.6$} & \multicolumn{2}{|c|}{$30.03 \pm 1.5$} \\
\hline
\end{tabular}

Table (5): Comparison of Total Mean Scores of Knowledge about Post-Operative Care Pre, Follow up of Study and Control Groups.

\begin{tabular}{|l|c|c|c|}
\hline Item & $\begin{array}{c}\text { Mean } \\
\text { \&S.D }\end{array}$ & t. test & P. value \\
\hline $\begin{array}{l}\text { Pretest: } \\
\text { Control group. }\end{array}$ & $28.53 \pm 11.0$ & 1.370 & 0.176 \\
Study group. & $28.53 \pm 11.1$ & & \\
\hline $\begin{array}{l}\text { Posttest: } \\
\text { Control group. }\end{array}$ & $31.003 \pm 3.6$ & 16.843 & $\mathbf{0 . 0 0 0}$ \\
Study group. & $93.20 \pm 17.9$ & & \\
\hline $\begin{array}{l}\text { Follow up: } \\
\text { Control group }\end{array}$ & $30.03 \pm 1.5$ & 13.165 & $\mathbf{0 . 0 0 0}$ \\
Study group. & $73.03 \pm 9.5$ & & \\
\hline $\begin{array}{l}\text { Study group: } \\
\text { Pretest. }\end{array}$ & $28.53 \pm 11.1$ & 18.348 & $\mathbf{0 . 0 0 0}$ \\
Posttest. & $93.20 \pm 17.9$ & & \\
\hline $\begin{array}{l}\text { Study group: } \\
\text { Pretest. }\end{array}$ & $28.53 \pm 11.1$ & 14.343 & $\mathbf{0 . 0 0 0}$ \\
Follow up. & $73.03 \pm 9.5$ & & \\
\hline $\begin{array}{l}\text { Study group: } \\
\text { Posttest. }\end{array}$ & $93.20 \pm 17.9$ & 13.965 & $\mathbf{0 . 0 0 0}$ \\
Follow up. & $73.03 \pm 9.5$ & & \\
\hline
\end{tabular}

$\mathbf{P} \leq \mathbf{0 . 0 0 0}$ 
Table (6): Comparison of Mean Scores of Total Knowledge of Mothers about PostOperative Care in the Study Group (Pre, Post and Follow up the Intervention).

\begin{tabular}{|c|c|c|c|c|c|c|c|c|}
\hline \multirow[t]{3}{*}{ Item } & \multicolumn{6}{|c|}{ Study Group $(\mathbf{N}=30)$} & \multirow[t]{3}{*}{ f. test } & \multirow{3}{*}{$\begin{array}{c}P . \\
\text { Value }\end{array}$} \\
\hline & \multicolumn{2}{|c|}{ Pre } & \multicolumn{2}{|c|}{ Post } & \multicolumn{2}{|c|}{ Follow Up } & & \\
\hline & Mean & S. D. & Mean & S.D. & Mean & S.D. & & \\
\hline $\begin{array}{l}\text { Sleeping } \\
\text { position after } \\
\text { operation. }\end{array}$ & 0.133 & 0.345 & 0.033 & 0.1825 & 0.4000 & 0.4982 & 8.0600 & 0.001 \\
\hline Nutrition. & 0.700 & 0.7943 & 1.5333 & 0.6288 & 2.0000 & 0.8304 & 22.745 & 0.000 \\
\hline $\begin{array}{l}\text { Care of } \\
\text { vomiting child. }\end{array}$ & 3.333 & 2.0228 & 11.266 & 3.0730 & 6.8333 & 1.3666 & 92.358 & 0.000 \\
\hline Activities. & 0.766 & 0.7738 & 1.800 & 0.4068 & 1.8333 & 0.3790 & 36.452 & 0.000 \\
\hline $\begin{array}{l}\text { Care of feverish } \\
\text { child. }\end{array}$ & 2.866 & 1.3321 & 7.100 & 1.7090 & 5.3667 & 1.5421 & 57.628 & 0.000 \\
\hline $\begin{array}{l}\text { Care of air way } \\
\text { and cough. }\end{array}$ & 2.000 & 1.5536 & 8.766 & 2.1444 & 6.4667 & 1.6760 & 108.47 & 0.000 \\
\hline Care of pain. & 3.500 & 1.1962 & 7.033 & 1.1885 & 5.1000 & 1.0938 & 69.732 & 0.000 \\
\hline $\begin{array}{l}\text { Medication } \\
\text { administration. }\end{array}$ & 3.000 & 0.0000 & 3.000 & 0.0000 & 3.0000 & 0.0000 & --- & ---- \\
\hline $\begin{array}{l}\text { Prevention of } \\
\text { increased } \\
\text { intarabdominal } \\
\text { pressure. }\end{array}$ & 1.666 & 1.3217 & 2.233 & 0.8976 & 2.5667 & 0.8172 & 5.786 & 0.000 \\
\hline Wound care. & 5.433 & 2.7251 & 17.93 & 4.1434 & 10.766 & 1.9596 & 124.52 & 0.000 \\
\hline $\begin{array}{l}\text { Urinary system } \\
\text { care. }\end{array}$ & 1.766 & 1.2507 & 6.333 & 1.0283 & 4.2667 & 1.0482 & 126.49 & 0.000 \\
\hline $\begin{array}{l}\text { Infection } \\
\text { prevention. }\end{array}$ & 4.933 & 4.1683 & 23.03 & 5.46136 & 13.7333 & 2.61209 & 136.478 & 0.000 \\
\hline Follow up care. & 0.733 & 0.4497 & 1.000 & 0.00000 & 1.0000 & 0.00000 & 10.545 & 0.000 \\
\hline
\end{tabular}

P. $\leq \mathbf{0 . 0 0 1}$ 
Table (7): Comparison of Posttest Knowledge of Mothers about Post-Operative Care between Control and Study Groups.

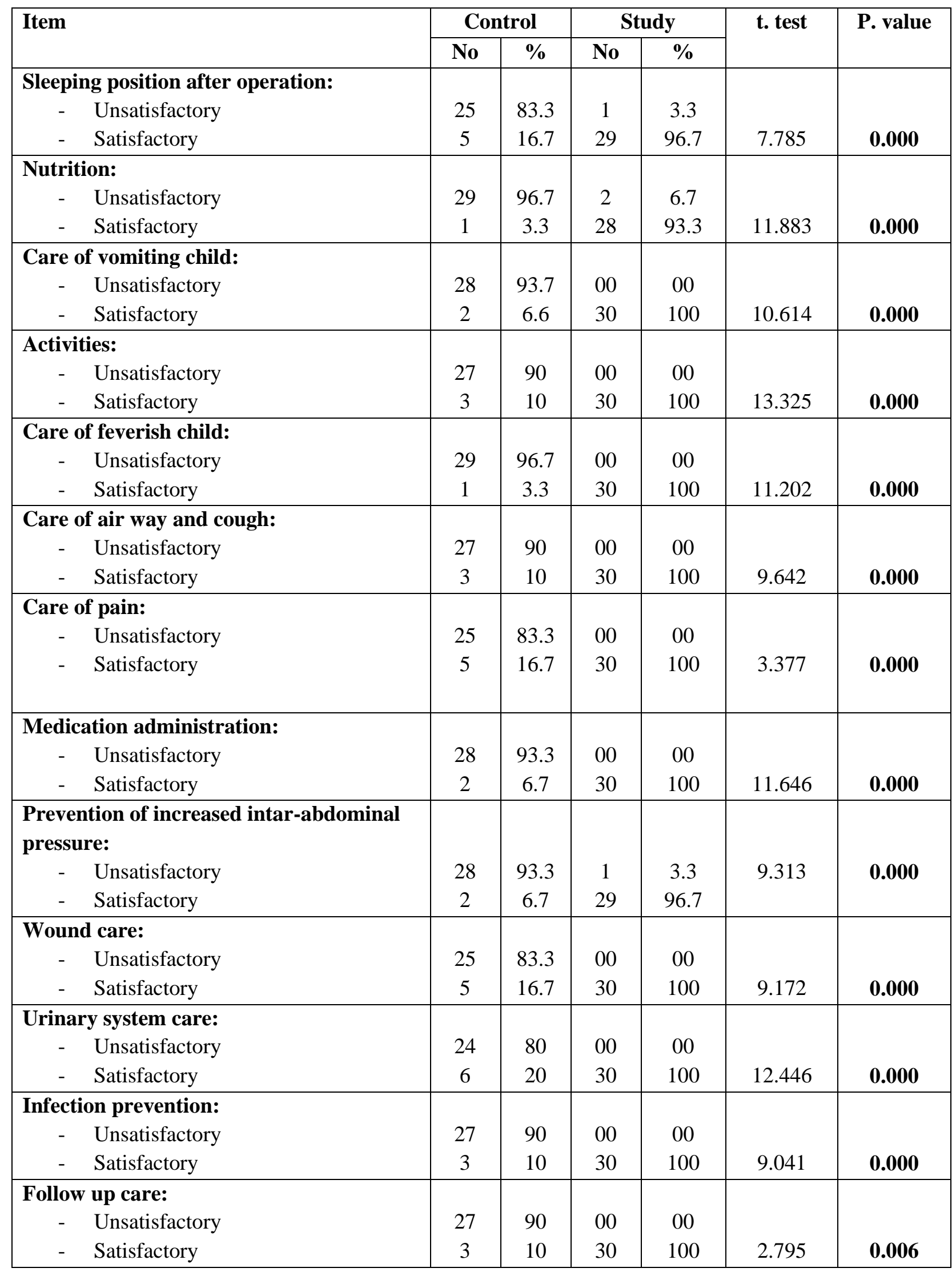


Table (8): Comparison of Follow up Knowledge of Mothers about Post-Operative Care between Control and Study Groups.

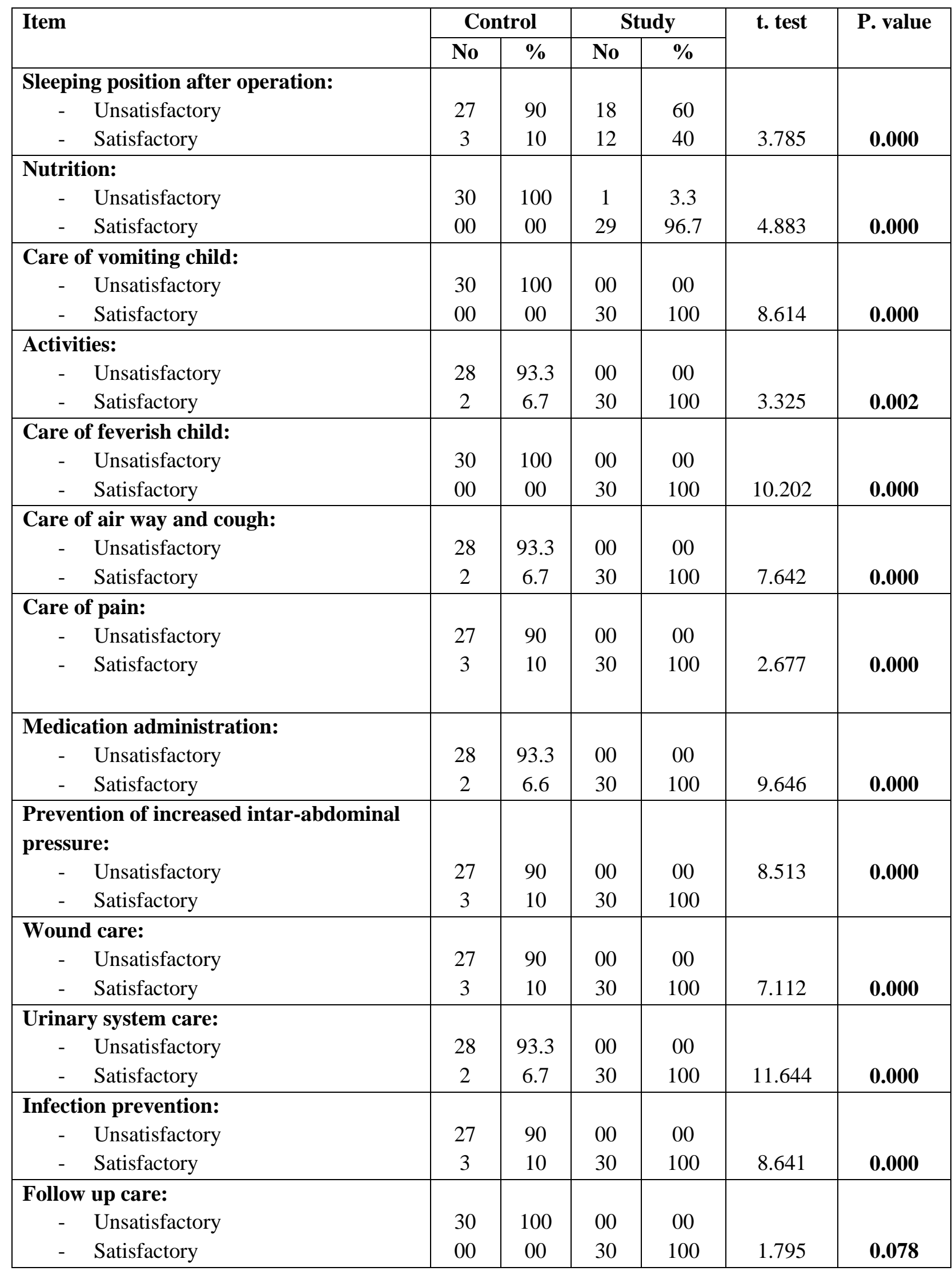


Table (9): Comparison of Post-Operative Complains of Children in the Study and Control Group.

\begin{tabular}{|c|c|c|c|c|c|c|c|c|}
\hline \multirow[t]{3}{*}{ Item } & \multicolumn{4}{|c|}{ Study Group } & \multicolumn{4}{|c|}{ Control Group } \\
\hline & \multicolumn{2}{|c|}{$\begin{array}{c}\text { Phone follow up } \\
\text { complains/ } \\
\text { complications }\end{array}$} & \multicolumn{2}{|c|}{$\begin{array}{l}\text { Follow up clinic } \\
\text { visit complains/ } \\
\text { complications }\end{array}$} & \multicolumn{2}{|c|}{$\begin{array}{c}\text { Phone follow up } \\
\text { complains/ } \\
\text { Complications }\end{array}$} & \multicolumn{2}{|c|}{$\begin{array}{l}\text { Follow up clinic } \\
\text { visit complains } \\
\text { complications }\end{array}$} \\
\hline & No & $\%$ & No & $\%$ & No & $\%$ & No & $\%$ \\
\hline 1- Bleeding & 00 & 00 & 00 & 00 & 00 & 00 & 8 & 26.6 \\
\hline 2- Fever & 9 & 30 & 00 & 00 & 00 & 00 & 13 & 43.3 \\
\hline 3- Pain & 7 & 23.3 & 00 & 00 & 00 & 00 & 6 & 20 \\
\hline 4- Vomiting & 6 & 10 & 00 & 00 & 00 & 00 & 7 & 23.3 \\
\hline $\begin{array}{l}\text { 5- urinary } \\
\text { problems } \\
\text { (Catheter } \\
\text { removal } \\
\text { (hypospadias, } \\
\text { dysuria) }\end{array}$ & 00 & 00 & 00 & 00 & 00 & 00 & 3 & 10 \\
\hline $\begin{array}{l}\text { 6- Abscess } \\
\text { formation } \\
\text { (complication) }\end{array}$ & 00 & 00 & 00 & 00 & 00 & 00 & 2 & 6.7 \\
\hline $\begin{array}{l}\text { 7- Wound skin } \\
\text { inflammation }\end{array}$ & 3 & 10 & 00 & 00 & 00 & 00 & 6 & 20 \\
\hline $\begin{array}{l}\text { 8- Respiratory } \\
\text { problem (cough } \\
\text { and difficulty } \\
\text { breathing) }\end{array}$ & 8 & 26.6 & 00 & 00 & 00 & 00 & 3 & 10 \\
\hline
\end{tabular}

The numbers in the table is not reflecting the number of children as some children had more than one complain. 
Table (10): Follow up Phone Calls of Study Group.

\begin{tabular}{|c|c|c|c|c|}
\hline \multicolumn{5}{|c|}{ Follow up phone calls } \\
\hline Total number & $\begin{array}{c}\text { Minim } \\
\text { duration in } \\
\text { minutes }\end{array}$ & $\begin{array}{c}\text { Maximum } \\
\text { duration in } \\
\text { minutes }\end{array}$ & $\begin{array}{c}\text { Mean duration } \\
\text { in minutes }\end{array}$ & $\begin{array}{c}\text { St. Deviation in } \\
\text { minutes }\end{array}$ \\
\hline 98 & 2.00 & 20.00 & 6.7755 & 4.33288 \\
\hline
\end{tabular}

Table (11): Correlation Matrix of Mothers' Knowledge Scores about Post-Operative Care and Their Characteristics in the Study Group $(\mathrm{N}=30)$.

\begin{tabular}{|l|c|c|c|c|c|c|}
\hline Item & \multicolumn{2}{l|}{$\begin{array}{l}\text { Pre intervention } \\
\text { knowledge } \\
\text { score }\end{array}$} & \multicolumn{2}{l|}{$\begin{array}{l}\text { Post intervention } \\
\text { knowledge score }\end{array}$} & \multicolumn{2}{l|}{$\begin{array}{l}\text { Follow up } \\
\text { intervention } \\
\text { knowledge score }\end{array}$} \\
\cline { 2 - 7 } & $\mathbf{r .}$ & $\begin{array}{c}\text { P. } \\
\text { value }\end{array}$ & r. & P. value & r. & P. value \\
\hline $\begin{array}{l}\text { Pre intervention } \\
\text { knowledge score }\end{array}$ & -- & -- & 0.430 & $\mathbf{0 . 0 1}$ & 0.022 & 0.908 \\
\hline $\begin{array}{l}\text { Post intervention } \\
\text { Knowledge score }\end{array}$ & 0.430 & $\mathbf{0 . 0 1}$ & -- & -- & 0.484 & $\mathbf{0 . 0 0 7}$ \\
\hline Mother age & 0.025 & 0.896 & 0.141 & 0.458 & -0.459 & $\mathbf{0 . 0 1}$ \\
& & & & & & \\
\hline
\end{tabular}

P. $\leq 0.05, P . \leq 0.01$ 


\section{Discussion}

Telenursing is a technology-based nursing service that was created to provide convenience to health services for patients The existence of telenursing for health services is based on many things, such as: the availability of limited human resources which makes it is unable to reach more patients, the limited capacity of hospitals and infrastructure, the need to minimize the risk of exposure to infection between patients and health workers, and the access to health service ${ }^{(21)}$. So the aim of the current study is to evaluate the effect of telenursing intervention program on mothers' knowledge about postoperative care for one day surgery children

Regarding socio-demographic data of children and their mothers in study and control group the findings revealed that there was no statistical significant difference, in addition no significant difference between two groups regarding diagnosis which reflect the homogeneity of study sample.

Concerning knowledge level the results illustrated that all mothers in control and study groups' pre the program had unsatisfactory knowledge level and there was no statistical significant difference between the two groups in the total mean score of knowledge about post-operative care. In prospective randomized controlled study by Gerceker, Muslu, and Yardimci (2016) (22), who evaluated children's postoperative symptoms at home after outpatient surgery through nurse-led telephone counseling, they stated that before discharge, it is important to give the parents adequate information about wound healing, changing the dressings, and the signs of infection. Postoperatively, there may be changes in the child's body temperature and blood pressure, nausea, vomiting, bloating, changes in appetite, and stomachache, possibly caused by anesthetic agents. Browne et al (2013) ${ }^{(23)}$, reported that in this short period, it is the nurses' responsibility to reduce the child's pain, address and inform the mother about the child's home care and possible complications that arise in children at home and to manage their children's symptoms during recovery period.

The current study results may be due the time between the operation and the child's discharge is very short in one day surgery. The short time between discharge and surgery may unable parents to ask sufficient questions which also effect on the management of complications.

As regard to the most frequent postoperative complains of children the findings showed that in control group fever, bleeding, and vomiting were the most, while in study group it was 
respiratory problems and pain. All children in the study group were managed immediately by the researchers on phone call while all the control group children presented to the surgical follow up clinic with the complaints. Also none in the study group had shown any postoperative complications while (10\% and 6.7\%) in control group had abscess formation and urinary catheter removal respectively. This difference in current study findings is most likely due to daily follow up by phone call which improved pain management by the mothers in the study group. These findings lead to accept research hypothesis number two and supported by similar studies.

Similarly, Souza-Junior, et al. (2016) ${ }^{(24)}$, who stated that pain at the surgical site is the primary symptom among the postoperative problems experienced by pediatric patients. It is known that families experience difficulties in managing children's pain. The use of analgesics and pain relief methods for effective pain management reduces admissions to hospital due to pain. After one day surgery, patients can experience bleeding, pain, and wound discharge at the surgical site and some parents have difficulties with wound care and dressing changes.

Kassmann, et al. (2012) (25), who emphasized that telephone counseling, is a way to control patients' symptoms by contact with healthcare professionals whenever they need information or have a problem in the postoperative period, and creates a sense of trust in patients and their families. When the parents receive telephone counseling for their child's problems, it reduces unnecessary hospital admissions, anxiety, and undesirable situations, such as the greater use of painkillers ${ }^{(4)}$.

In the same line Gerceker, Muslu, and Yardimci $(2016)^{(22)}$, who reported that the most common postoperative symptom was pain. Intervention group parents were given information related to pain management by nurse-led telephone counseling, including use of analgesics and an explanation of non-pharmacological pain relief methods, while there were no visits to the emergency department for pain symptoms in the intervention group while control group visited emergency services due to pain.

In a prospective study by Xin, et al (2019) ${ }^{(26)}$,who studied efficacy of telephone follow-up in children tonsillectomy with day surgery, the sample consisted of 863 children randomly assigned to receive clinic visit after discharge or 1 to 14 days telephone follow-up after discharge. Compared with clinical visit, children in telephone follow-up group presented with 
less pain in early stage after surgery and better food and drink intake telephone follow-up significantly reduces pain intensity, promotes analgesia use and fluid intake and reduces the search for healthcare services. They suggested that a follow-up telephone call is a safe and costeffective method of postoperative management for pediatric patients who have undergone tonsillectomy.

The present study results revealed that there were positive highly statistical significant differences between the total mean scores of mothers' knowledge pre, post and after one month following the intervention. Regarding this findings, it was evident that the present study results supported the research hypotheses one as the total mean scores knowledge of intervention group in post and follow up phase of implementation of telenursing program were more than before compared with control group with highly statically significant difference. These results are supported by many studies in the same context. In a review by Al Afik, and Pandin $(2020)^{(27)}$ to identify the important role of telenursing in improving nursing services for patients The results of a review of 10 articles found that the form of nursing services with telenursing could prove long-distance service, time efficiency and funding allocation. The 21st century global nursing paradigm was developed with the help of technology to meet the needs of services that have distance, physical and cost limitations. They add that telenursing is a solution to answer the challenges of the demands of efficient and quality health care services. The summary of 10 articles shows that there are significant benefits to the use of technology to support health services. Nursing has many ways to facilitate the patient's need for nursing care and/or in managing management and conducting distance education that is more efficient and can reduce costs.

Dehkordi, et al (2020) ${ }^{(28)}$ and Rakhmawati $(2020)^{(15)}$ reported that some evidence related to telenursing illustrated that it could be used for consultation, education, monitoring, and the evaluation of health care outcomes. Telenursing is effective with increasing the needs of public health. Finally In a recent systematic review by Gudnadottir, et al (2021) ${ }^{(29)}$ to study what the current literature reports on the effect of post-operative telephone counseling and Internet support on pain and recovery after pediatric tonsil surgery. They highlighted that nursing interventions such as presurgical preparations and nurse telephone follow up may have a positive influence on children's postoperative recovery. They also showed the need of further nursing 
studies within the area in order to be able to generalize results and thus draw evidence based conclusions.

\section{Conclusion}

The current study concluded that telenursing intervention program positively improved mother's knowledge in intervention group after implementation than before compared with control group.

\section{Recommendations}

- Applying telenursing intervention in nursing care to facilitate contact of mothers with nurses whenever they need

- Further researches needed to emphasize the effect of telenursing intervention on improving mother's knowledge about post-operative care for a larger sample and a longer period of time.

\section{Acknowledgment}

The authors gratefully thank and appreciate mothers and their children for their cooperation and acceptance to participate in the study. Also deep gratitude is presented to Professor Doctor Sherif Nabahan Kadah, HOD of surgical department at Cairo University Specialized Pediatric Hospital (CUSPH) Al-Monirah Hospital, and director of surgical outpatient clinic at Cairo University Specialized Pediatric Hospital (CUSP) and follow up surgical clinic at Center for
Social and Preventive Medicine (CSPM) affiliated to Cairo University; as he facilitated and greatly supported our research efforts during the period of data collection.

\section{References}

1. Chukwubuike $\mathrm{K}$, Ikemefuna $\mathrm{O}$, Nduagubam O. Paediatric day case surgical practice at a tertiary hospital in Enugu. Health Care \& Global Health, 2019; $\quad$ 1(1): $\quad$ 55-59. https://doi.org/10.22258/hgh.home: an exploratory qualitative study home: journal of Clinical Nursing, 25, 26192628, doi: 10.1111/jocn.13307.

2. Bielby L, Moss R, Mo A, Mcquilten $\mathrm{Z}$, and Wood E, The role of the transfusion practionier in the management of anemia. VOXS, 2019; 15(1):82-90.

3. Okpara P. Challenges of nursing care of the pediatric surgical patient. Afr J Paediatr Surg, 2018; 15(3-4): 154157.Published online 2020 doi: 10.4103/ajps.AJPS_28_13.

4. Longard J, Twycross A, Williams A, Hong $\mathrm{P}$ and Chorney J. Parents' experiences of managing their child's postoperative pain at home: An exploratory qualitative study .J Clin Nurs, 2016; 25(17-18):2619-28.

5. $\mathrm{Yu} \mathrm{K}, \mathrm{Kim}$ J. Effects of a post tonsillectomy management program 
using a mobile instant messenger on parents' knowledge and anxiety, and their children's compliance, bleeding, and pain. Spec Pediatric Nursing, 2019; 24(4):e12270.

DOI:

10.1111/jspn.12270.

6. Zhu Y, Chan W, Liam W, Xiao C, Lim C, Cheng K, and Hong-Gu H. Effects of postoperative pain management educational interventions on the outcomes of parents and their children who underwent an inpatient elective surgery: A randomized controlled trial. J Adv Nurs, 2018; 74(7):1517-1530. doi: 10.1111/jan.13573.

7. Australian Confederation of Pediatric and Child Health Nurses Competencies for the Specialist Pediatric and Child Health Nurse). $2^{\text {nd }}$ ed.; Sydney. 2016.

8. Association of Anesthetists and the British Association of Day- Surgery. Guidelines for Day-case surgery. 2019, ://doi.org/10.1111/anae.14639.

[Accessed on May 2021].

9. Lucila R, Machado S, Rodrigues, Thaíla, Bortoli P, Débora C and Silvan K. Parents' participation in managing their children's postoperative pain at home: An integrative literature review. Journal of Pain Management Nursing, 2019; 20(5): 444-454 https://doi.org/10.1016/j.pmn.2018.12. 002.
10. Chaupi H. Artículo especial prospective applicability of e-health services: An overview of advantages of telemedicine and telenursing. Health Care \& Global Health, 2017; 1(1): 5559.

11. Pan American Health Organization. Framework for the Implementation of a Tele-medicine Service 2019, https://www3.paho.org/hq/index.php?o ption=com_content $\&$ view=article $\&$ id $=$ 15138:nursing-staff-are-vital-formaking-progress-towards-universalhealth\&Itemid=1926\&lang=en[availabl e 2019].

12. Toffoletto $M$ and Tello G. Telenursing in care, education and management in Latin America and the Caribbean: an integrative review. Rev.Bras.Enferm., 2020;73 (5)Brasília. Availablefrom: htt ps://www.paho.org/ict4health/index.ph p?option $=$ com_content $\&$ view $=$ article $\&$ id=9684:telehealth\&Itemid=193\&lang =es.

13. Mozafari S, Khorshidi A and Lotfi. Comparing the effects of face-to-face and telenursing education on the quality of family caregivers caring in patients with cancer. Journal of Family Medicine and Primary Care, 2018; 7(6): 1209-1215. https://doi.org/

14. Pepito J, Loscin R. Can nurses remain 
relevant in a technologically advanced future? International Journal of Nursing Sciences, 2019; 6: 106-110.

15. Rakhmawati W. Is telenursing a solution for managing the impact of Covid-19 on the mental health of school aged children? Belitung Nursing Journal, 2020; $6 \quad$ (5): 182-184. https://doi.org/10.33546/bnj.1168.

16. Royal College of Nursing. 2020, eHealth.https://www.rcn.org.uk/clinical -topics/ehealth [available in 2020].

17. Zhang $X$ and Yuxia Z. Strengthening the power of nurses in combating COVID-19. Journal of Nursing Management, 2020; 180. https://doi.org/10.1111/jonm.13023.

18. Abusaad F, Sarhan M. Exercise training program and telenursing effects on depression and fatigue level in B- Thalassemia Major children. American Journal of Nursing Science, 2016; 5 (5): 191-200.

19. Polit D, and Beck C. Essentials of nursing research: Appraising evidence for nursing practice. $7^{\text {th }}$. ed., Lippincott and Williams, London.2017.

20. International Fund for Agricultural Development. Calculating the Sample Size.2021.

http://www.ifad.org/gender/tools/hfs/an thropometry/ant 3.htm[2021]
21. Rambur B, Palumbo M, Nurkanovic M. Prevalence of telehealth in nursing: Implications for regulation and education in the era of value-based care. Policy Polit Nurs Pract., 2019; 20(2):64-73.

22. Gerceker G, Muslu G, and Yardimci F. Children's postoperative symptoms at home through nurse-led telephone counseling and its effects on parents' anxiety: A randomized controlled trial. J Spec Pediatr Nurs., 2016; 21(4):189199.

23. Browne N, Flanigan L, McComiskey C and Pieper P. (2013). Nursing care of the pediatric surgical patient. Burlington, MA: Jones \& Bartlett Learning.

24. Souza-Junior V, Mendes I, Mazzo A, and Godoy S. Application of telenursing in nursing practice: An integrative literature review. Applied Nursing Research, (2016); 29: 254260.

25. Kassmann B, Docherty S, Rice H, Bailey D, and Schweitzer M. Telephone follow-up for pediatric ambulatory surgery: Parent and provider satisfaction. Journal of Pediatric Nursing,2012;27(6):715-724. 26. Xin Y, Li X, Du J, Cheng J, Yi C, Mao H. Efficacy of telephone follow- up in children 
tonsillectomy with day surgery. Indian J. Pediatr., 2019; 86(3):263266.

27. Al Afik $G$ and Pandin $M$. Telenursing as a new nursing paradigm in the 21 century: A literature review. Preprints (www.preprints.org).:10.20944/pre prints202103.0704.v1.[Accessed on October 2020].

28. Dehkordi F, Heidari H, Masoodi R, Sedehi M, and Khajeali F. Telenursing strategies in Iran: A narrative literature review. Int $\mathrm{J}$ Epidemiol Health Sci., 2020; 1(3): $1-15$.

29. Gudnadottir G, Persson R, Drevenhorn E, Olofsson E, and Rosén H. The effect of telephone counseling and internet-based support on pain and recovery after tonsil surgery in children -a systematic review. International Journal of Nursing Studies Advances, 2021; 3: 100027. https://doi.org/10.1016/j.ijnsa..1000 27[ Accessed on October 2021]. 